\title{
Knowledge, Attitude, and Utilization of Traditional Medicine among the Communities of Merawi Town, Northwest Ethiopia: A Cross-Sectional Study
}

\author{
Samuel Masresha Wassie, ${ }^{1}$ Leul Lisanework Aragie, ${ }^{1}$ \\ Belaynew Wasie Taye, ${ }^{2}$ and Laychiluh Bantie Mekonnen ${ }^{1}$ \\ ${ }^{1}$ School of Medicine, College of Medicine and Health Sciences, Bahir Dar University, P.O. Box 79, Bahir Dar, Ethiopia \\ ${ }^{2}$ School of Public Health, College of Medicine and Health Sciences, Bahir Dar University, P.O. Box 79, Bahir Dar, Ethiopia \\ Correspondence should be addressed to Laychiluh Bantie Mekonnen; laychiluh.bantie@gmail.com
}

Received 7 July 2015; Accepted 20 September 2015

Academic Editor: Karin Kraft

Copyright (c) 2015 Samuel Masresha Wassie et al. This is an open access article distributed under the Creative Commons Attribution License, which permits unrestricted use, distribution, and reproduction in any medium, provided the original work is properly cited.

Background. In Ethiopia, up to $80 \%$ of the population use traditional medicine for primary health care. Studies on the current knowledge and practices of communities in the era of modern health care expansion are lacking. Therefore, this study is aimed at assessing the knowledge, attitude, and practice of traditional medicine among communities in Merawi town. Methods. A descriptive cross-sectional study was carried out among 403 residents of Merawi town. A systematic random sampling was used to select households. Data was collected through house to house interview. Results. 392 out of 403 questionnaires were analysed. Among the participants, $220(56.1 \%)$ were female. The mean ( \pm s.d.) age of the participants was $32.5( \pm 12.4)$ years. Nearly two-thirds, 241 (61.5\%), of study participants have good knowledge about traditional medicines. Three-quarters of participants prefer modern medicine to traditional drugs. $70.9 \%$ of participants had the experience of personal use of traditional therapies. Conclusions. The population in Merawi has good knowledge with high acceptability and use of traditional medicine. The main reasons for high acceptability and practice were cultural acceptability, lesser cost, and good outcome of traditional medicine.

\section{Introduction}

Traditional medicine (TM) refers to health practice, approach, knowledge, and beliefs incorporating plant, animal, and mineral based medicines, spiritual therapies, manual techniques, and exercises applied singularly or in combination to treat, diagnose, and prevent illness or maintain wellbeing [1].

The widespread use of TM has resulted in traditional health care becoming a lucrative, multinational business. Billions of US dollars are spent annually on traditional medicine in many developed countries. For example, in 2012, 32 billion dollars were spent in the United States of America on dietary supplements, an amount expected to increase to 60 billion dollars in 2021 [2]. The World Health Organization estimates that the global market of traditional medicine is approximately US $\$ 83$ billion annually [3]. Traditional medicines also contribute to the development of pharmaceutical treatments. As much as one-third to one-half of pharmaceutical drugs was originally derived from plants [4]. Some prominent examples including digitalis, morphine, quinine, and vinca alkaloids were obtained from plant sources [5].

Traditional medicine does more than providing raw materials for pharmaceuticals; holders of traditional knowledge often have valuable knowledge for new drug development. Traditional knowledge can provide valuable guidance in selecting and obtaining plant material of potential therapeutic interest. Bioactive compounds derived from currently used herbal medicines are more likely to have minimal toxicity, and a long history of clinical use suggests that herbal medicine may be clinically effective. Plant-derived compounds used as drugs are generally used in ways that correlate directly with their traditional uses as plant medicines [6]. 
Countries in Africa, Asia, and Latin America use TM to help meet some of their primary health care needs [79]. Despite western medicine becoming more widespread in Ethiopia, Ethiopians tend to rely more on TM. Modern health services remain concentrated in urban areas and have failed to keep pace with the growing population, keeping health care access out of reach for most Ethiopians living in rural Ethiopia. Because TM is culturally entrenched, accessible, and affordable, up to $80 \%$ of the Ethiopian population relies on traditional remedies as a primary source of health care $[7,10]$.

Some studies have also revealed that Ethiopians use TM due to lack of access to modern health care facilities. However, the current Ethiopian health care system is a primary health care focused system which improves access to modern medicine more than ever. But, both rural and urban populations continue to use traditional medicine. The reason behind this was found to be the cultural acceptability of TMPs [11].

Although traditional medicine plays an important role in Ethiopian society, knowledge about the extent and characteristics of traditional healing practices and practitioners is limited and has frequently been ignored in the national health system. This is also true in Merawi where such study on traditional medical practice (TMP) was not conducted in the past $[7,8,12]$. Based on the above insight the study focused mainly on identifying the knowledge, perceptions, and practice of TM through cross-sectional study in Merawi town, northwest Ethiopia.

By studying the knowledge, attitude, and practices of traditional medicine in Merawi town, our study will provide important data for the town administration and Amhara Regional Health Bureau to take appropriate controlling measures regarding the quality and safety of the practices. The study will also provide the baseline data for researchers for further investigations to determine the determining factors of TM uses.

\section{Method}

2.1. Study Design. A community based cross-sectional study design was used to assess knowledge, attitude, and utilization of the community towards traditional medicine, in Merawi town, 2015.

2.2. Study Setting. Study was conducted in Merawi town. Merawi is the capital of Mecha District found in northwest Ethiopia. It is found at a distance of $36 \mathrm{~km}$ from Bahir Dar. Its climatic condition is "Woina Dega." Currently, it has a total population of 40,635 people of which 18,597 (45.77\%) are males and 22,038 (54.23\%) females. There are about four private clinics, one public health center, and a newly constructed standardized hospital which will be officially opened soon for public service.

2.3. Population. All the households in Merawi town were the source population of the study. The study population included individuals aged greater than 18 years and living for at least six months in the town. The sampling units were households, while the study units were adult individuals available in the household during the interview, preferably the woman, where more than one adult were found.

2.4. Sample Size Calculation. Sample size was calculated based on the prevalence of knowledge, attitude, and practice based on the following assumptions: $P=80 \%$ prevalence of TM users in Ethiopia [7], $Z$ (1.96) is the value under standard normal table for confidence level of $95 \%$, margin of error $(d)=4 \%$, and using the formula for estimation of single population proportions $n=Z^{2} P(1-P) / d^{2}$. And adding a nonresponse rate of $5 \%$, the final sample size became 403 adults. $n$ is the required sample of the study.

2.5. Sampling Procedure. A systematic random sampling technique was used to select households. The first household was selected from the list of initial 6 households by lottery method. Then every 6 th household was selected and adults in the household were interviewed. In the presence of more than one adult the woman was interviewed as women took the highest responsibility in the care of family members. In the absence of woman, the husband or other adults were interviewed.

2.6. Data Collection Procedure. Data were collected using structured interviewer administered questionnaire adapted from standardized questionnaires used by international organizations, national studies such as Demographic and Health Survey, and published articles in peer-reviewed journals. Data were collected by trained data collectors using face-toface interview.

2.6.1. Data Quality Control. Intensive training was provided to data collectors about data collection techniques. Detail orientation was given to the data collectors about the study before data collection procedure starts. A translation of data collection instruments into local language was done. A pilot test was done on 40 ( $10 \%$ of the sample population) households to validate consistency of the questions and data collection tool.

2.7. Study Variables. The outcome variables of the study were knowledge, attitude, and utilization of the community on TMs. The explanatory variables were age of interviewee, monthly family income, educational status, distance from nearby health facility, and membership of community health insurance.

2.8. Data Management and Analysis. Data were checked for completeness and consistency and entered into SPSS version 20 by principal investigators, cleaned, and analyzed. The results were presented using simple frequencies with percentages in appropriate tables to display the descriptive part of the result.

Five yes or no questions were asked for each respondent regarding harmful TMs, side effects of TMs, and importance of training about TMs. The number of questions for which 
the respondent gave correct responses was counted and scored. This score was then pooled together and the mean score was computed to determine the overall knowledge of respondents; respondents who score greater than or equal to the mean value were grouped to have good knowledge and and those who score less than the mean value poor knowledge level. The attitude of the respondents was assessed using eight yes or no questions focusing on the history of training about $\mathrm{TM}$, recommending these methods to the others, effectiveness of methods for applied cases, interest to learn TCM, and choice of training methods.

2.9. Ethical Issues. Formal letter of approval was obtained from the Ethical Review Board of College of Medicine and Health Science to Merawi town administration. Each participant of the study was informed about confidentiality. Each participant of the study agreed to participate voluntarily. Participants were allowed to discontinue the interview when they needed. All participants of the study declared their willingness to participate and approved by their verbal consents.

\section{Results}

3.1. Sociodemographic Characteristics. A total of 392 respondents, with a response rate of $97.3 \%$, were studied. Among the participants, 220 were females $(56.1 \%)$ and the rest were males. Ages of participants ranged from 18 to 85 (mean age of the participants was $32.54 \pm 12.44$ years). Regarding the religion, $286(73 \%)$ of the study participants were follower of Orthodox Christianity followed by Muslims 85 (23.7). From the total respondents about 75 (19.1\%) were government employees. 198 (50.54\%) participants have family size of 3 to 5 family members. With respect to income 83 (21.8\%) of the respondents reported that their annual incomes were above the mean annual income (33318.49 birr). Large number of respondents, $115(29.3 \%)$, cannot write and read while 113 (28.8\%) respondents attended secondary school. Two 208 $(53.1 \%)$ of the respondents were married (Table 1 ).

3.2. Knowledge about Traditional Medicine. The mean ( \pm ) value knowledge score was $4.4( \pm 0.97)$. The data in Table 2 shows that 241 (61.5\%) of the study participants were found to have good knowledge about TMs and 151 (39.5\%) had poor knowledge level. Most of the respondents 352 (89.8\%) responded that there is no harmful traditional practice. However, 379 (96.7\%) respondents knew that exposure to nonsterile material could result in HIV infection to the users (Table 2).

3.3. Attitude towards Traditional Medicine. Two hundred eighty-one $(71.7 \%)$ of the study participants prefer to use modern health service rather than traditional medicines (Figure 1). Regarding the effectiveness of the TMs, 275 (70.2\%) participants do not agree about effectiveness of TMs compared to modern health care service after use. Only 75 (19.1\%) participants recommend using TM therapy for others. Among the participants, 232 (59.2\%) believe TMs are still accepted in the community and 115 (49.5\%) respondents
TABLE 1: Sociodemographic characteristics of respondents, Merawi town, April 2015.

\begin{tabular}{|c|c|c|}
\hline Characteristic & Number of persons & Percent \\
\hline \multicolumn{3}{|l|}{ Sex } \\
\hline Male & 172 & 43.9 \\
\hline Female & 220 & 56.1 \\
\hline \multicolumn{3}{|l|}{ Age of respondent (years) } \\
\hline $18-28$ & 187 & 47.7 \\
\hline $29-38$ & 95 & 24.3 \\
\hline $39-48$ & 66 & 16.8 \\
\hline$>49$ & 44 & 12.2 \\
\hline \multicolumn{3}{|l|}{ Occupation of respondent } \\
\hline Farmer & 12 & 3.0 \\
\hline Merchant & 90 & 23 \\
\hline Government employee & 77 & 19.61 \\
\hline Student & 58 & 14.8 \\
\hline Self-employed & 23 & 5.8 \\
\hline Unemployed & 28 & 7.1 \\
\hline Housewife & 74 & 18.9 \\
\hline Others & 30 & 7.7 \\
\hline \multicolumn{3}{|l|}{ Annual income } \\
\hline $2,400-50,000$ & 199 & 50.9 \\
\hline $50001-100,000$ & 34 & 8.8 \\
\hline$>100,000$ & 5 & 1.3 \\
\hline \multicolumn{3}{|l|}{ Marital status of respondent } \\
\hline Married & 208 & 53.2 \\
\hline Never married & 147 & 37.6 \\
\hline Divorced & 10 & 2.6 \\
\hline Widowed & 26 & 6.6 \\
\hline \multicolumn{3}{|l|}{ Education of respondent } \\
\hline Illiterate & 115 & 29.3 \\
\hline Primary school & 89 & 22.7 \\
\hline Secondary school & 113 & 28.8 \\
\hline Higher education & 14 & 3.6 \\
\hline
\end{tabular}

agree that the reason is cultural acceptability and $42.2 \%$ account the good outcome of TM after they use them.

Sixty nine (17.6\%) participants have previously attended education or training about the benefits and adverse effects of traditional medicine. Majority, 354 (90.3\%), of the respondents strongly felt that they want training about these issues (Table 2) and 210 (53.6) of them prefer the public awareness creation about TMs.

About 278 (70.9\%) participants had used different types of herbal medicines either by themselves or visited traditional healer at least once in their lifetime for treatment. Of those respondents, 171 (64\%) had used only herbal medication of different type as mode of treatment for various illnesses (Table 4). Furthermore, out of herbal medication users, $98.8 \%$ has used herbal medication for 6 months. Only $22(5.6 \%)$ respondents had history of concurrent use of modern medicines along with TMs. Aspirin, Paracetamol, Amoxicillin, and antacids are the commonest drugs used with TMs. Eighty-nine (22.7\%) respondents experienced adverse 
TABLE 2: Knowledge of Merawi residents of traditional medicines, April 2015.

\begin{tabular}{|c|c|c|}
\hline Characteristics & Frequency & Percentage \\
\hline \multicolumn{3}{|c|}{ There is no harmful traditional medicine } \\
\hline True & 352 & 89.8 \\
\hline False & 40 & 10.2 \\
\hline \multicolumn{3}{|c|}{$\begin{array}{l}\text { Traditional medicines have no adverse } \\
\text { effect }\end{array}$} \\
\hline True & 350 & 89.3 \\
\hline False & 42 & 10.7 \\
\hline \multicolumn{3}{|c|}{$\begin{array}{l}\text { Health education about risks and benefits } \\
\text { of traditional medicines is important }\end{array}$} \\
\hline True & 354 & 90.3 \\
\hline False & 38 & 9.7 \\
\hline \multicolumn{3}{|c|}{$\begin{array}{l}\text { Exposure to nonsterile material will } \\
\text { expose to HIV }\end{array}$} \\
\hline True & 379 & 96.7 \\
\hline False & 13 & 3.3 \\
\hline \multicolumn{3}{|c|}{$\begin{array}{l}\text { Traditional medicines are more effective } \\
\text { and safer than modern health services? }\end{array}$} \\
\hline True & 102 & 26 \\
\hline False & 290 & 84 \\
\hline
\end{tabular}

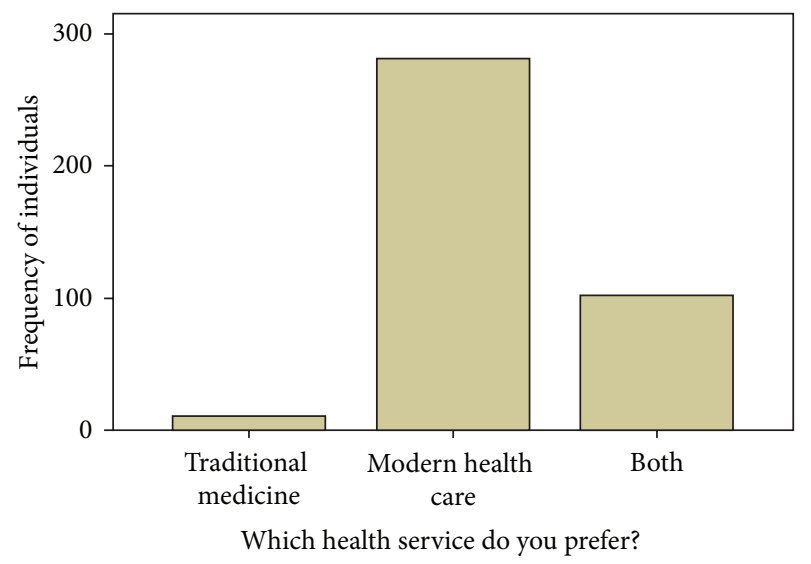

FIGURE 1: Preference of health care system and attitude of traditional medicine among Merawi residents, April 2015, utilization of traditional medicines.

effects in their family members due to traditional medicine therapy. The reported adverse effects include bleeding, abortion, visual loss, tetanus, jaundice, fistula, gastritis, psychosis, exacerbation of illness, paralysis, and even death (Table 3).

3.4. Factors Associated with Traditional Medicine Use. Association between independent variables and KAP scores on TMs was calculated using Pearson's Chi square. There was significant association between KAP scores and age $(P=$ $0.05)$, specially with age group between 18 and 28 and 29 and $38(P=0.02$ and 0.004 , resp.). Educational status was also significantly associated with KAP scores $(P=0.00)$. Moreover, occupation $(P=0.00)$ and effectiveness of TMs
(0.002) were found to be associated with KAP score on TMs (Table 4).

\section{Discussion}

The prevalence of TM use in our study is $70.9 \%$. Our finding is somewhat lower when compared to another study conducted in Ethiopia which states that the prevalence of traditional medicine use is $80 \%$ [13]. This is probably due to the sample size difference where the later takes large sample size. $70.9 \%$ prevalence is still high and this can be ascribed to the fact that majority of people in our study (59.2\%) believe that traditional medicine is still acceptable in the communities of Merawi town. The wider acceptability of traditional medicine in the town is because of cultural acceptability, easy accessibility, and affordability of traditional medicine compared to modern medicines and facilities [10, 14].

Among the practiced traditional medicine the commonest are herbal medication 64\%, uvulectomy $20.1 \%$ [15], and spiritual healing (7.6\%). $22.7 \%$ of the population experienced adverse effects after the use of traditional medicine and the commonest are bleeding, fistula, psychosis, and exacerbation of illness. This is different from population based study conducted in northern Ethiopia during 2005; the prevalence rates of uvulectomy and milk teeth extraction were $89 \%$ and $58 \%$, respectively [7]. This shows that as the level education of mother increased the use of harmful traditional medicine practice decreased, in addition to the fact that TMs vary together with cultural diversity of the country.

Our study revealed that $61.5 \%$ of the population has good knowledge about traditional medicines which is different from the study conducted in Lagos Nigeria in which $44.7 \%$ of the population had good knowledge [16]. The discrepancy in the results between the two studies might be associated with mainly the time gap in which the studies are conducted which changes the awareness of the population about traditional medicine and coverage of modern health care. The socioeconomic differences between the two towns (Lagos is the capital city of Nigeria, while Merawi is a Woreda town) might also contribute to the observed differences.

Our study also indicated that more than two-thirds $(82.4 \%)$ of the participants had no previous formal education on the benefits and adverse effects of traditional medicine, but majority (90.3\%) of participants showed interest to acquire education in this regard. Moreover, $53.6 \%$ of the participants best prefer the public health education as a means of awareness creation. These findings show that most of the participants in the study had positive attitude toward traditional medicine.

The participants have reported that they use many plant products for different disorders. The people prepare the plants in different dosage forms (liquid, solid, and gaseous forms) and administer them by mixing with water, tea, egg, and honey or without any mixing. Different studies also reported similar practices $[17,18]$. The plant preparations are mainly used once daily for few days (ranges from 1 day to 6 months). Most commonly used routes of administration are oral, topical, and inhalational routes of administration. Previous 


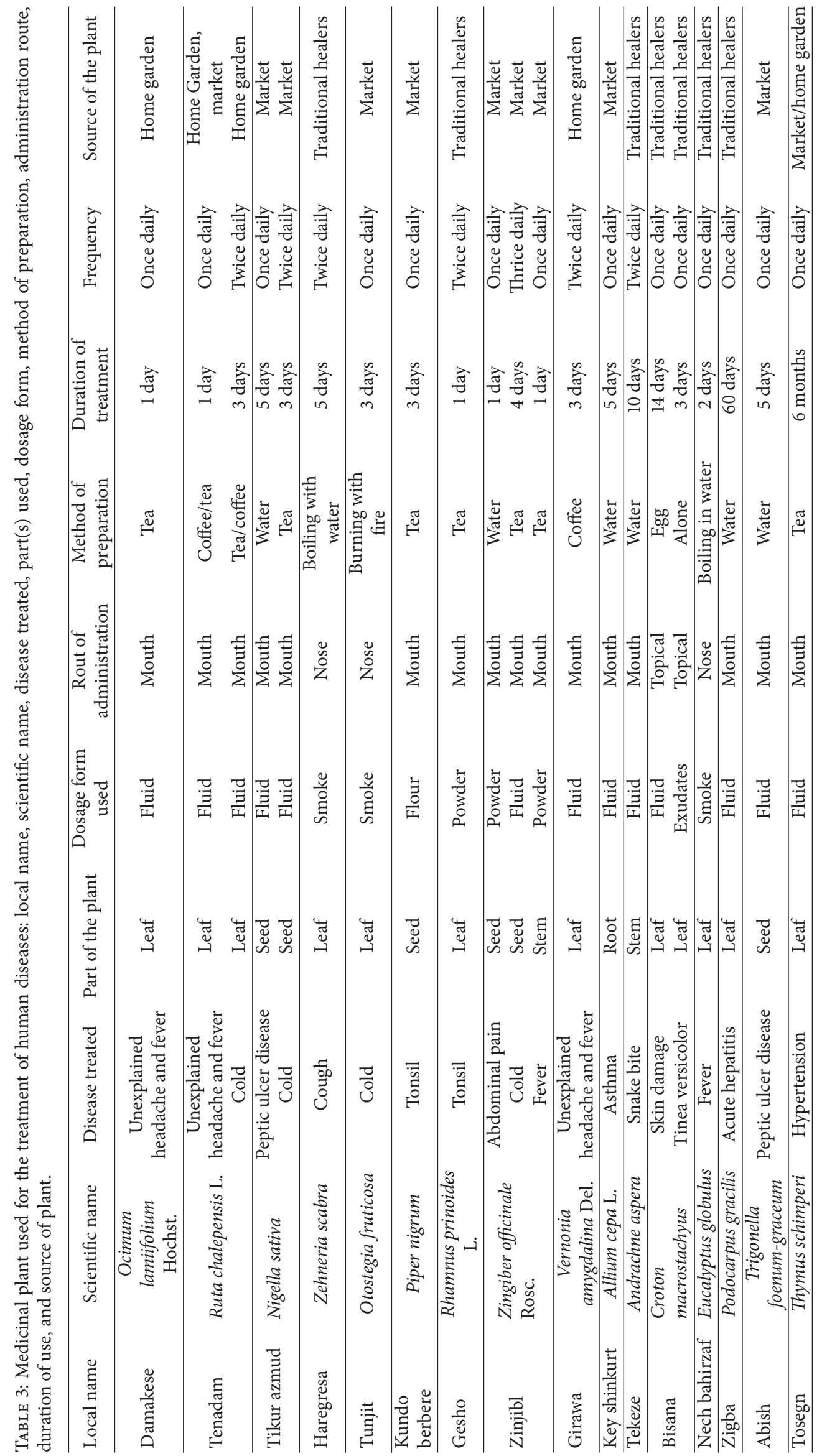


TABLE 4: Relationships between KAP scores about TMs and some key independent variables among study respondents of Merawi town, April 2014.

\begin{tabular}{lcc}
\hline Variable & $\chi^{2}$ & $P$ value \\
\hline Sex & 2.47 & 0.118 \\
Age & 33.05 & 0.05 \\
Annual income of the family & 4.25 & 0.834 \\
Religion & 2.01 & 0.919 \\
Occupation & 51.05 & 0.00 \\
Educational status & 37.38 & 0.00 \\
Family size & 30.98 & 0.056 \\
Effectiveness & 16.49 & 0.002 \\
Marital status & 5.84 & 0.212 \\
\hline
\end{tabular}

studies reported that oral, dermal, and nasal routes are the three most commonly used routes of administration which is in line with our study [18-20].

Many diseases such as headache, cough, peptic ulcer disease, asthma, cold, skin disease, hypertension, and others are reported to be treated with the different plant preparations in our study. Leaves, stems, and seeds were mainly used for treatment. The plants were obtained from home garden, market, or traditional medicine practitioner. Other studies done in different parts of Ethiopia have reported that leaves of the plants are the most commonly used parts of the plants for treatment of similar disorders/diseases [21-23].

In our study, we found that the use of traditional medicine was significantly associated with the age of the population; particularly age groups of 18-28 and 29-38 were highly associated with the level of traditional medicine use with $P$ value $<0.02$ and 0.004 , respectively. Educational status and occupation of the participants were found to be highly associated with the use of traditional medicine $(P$ value $=0)$. Religion, family size, annual income, and marital status were found to have no association with use of traditional medicine.

\section{Conclusions}

The population has good knowledge of the TM. The acceptability and prevalence of traditional medicine in the town are high and this is related to the cultural acceptability, easy accessibility, and affordability of TM. Lack of access to modern health service is also another factor which contributed to the high prevalence of TM use by the respondents. Herbal medication use is the most common type of TM practiced in the population. Herbal medications were used by the community to treat headache, cough, peptic ulcer disease, asthma, cold, skin disease, hypertension, and other related diseases. The herbal products which are mainly leaves, stems, and roots were obtained mainly from home garden. Bleeding, fistula, and psychosis are the major adverse effects of herbal medications reported by the population. Most of the population show interest to have education regarding the benefit and adverse effects of TM. Age group, economic status, and educational status were found to be highly associated with high prevalence of TM use, whereas family size, annual income, and religion were found to have no association with TM use.

\section{Conflict of Interests}

The authors declare that there are no competing interests.

\section{Authors' Contribution}

All the 4 authors developed the concept and developed the proposal. Leul Lisanework Aragie and Samuel Masresha Wassie collected, sorted, and analyzed the data. Laychiluh Bantie Mekonnen and Belaynew Wasie Taye supervised and followed the whole study process and wrote and reviewed the final paper. All the authors have read and approved the paper.

\section{Acknowledgments}

The authors would like to thank College of Medicine and Health Sciences for its material support. The authors also like to thank all the staff of Merawi town administrative office for their cooperation and for giving them the information they needed.

\section{References}

[1] WHO, Traditional Medicine Strategy 2002-2005, World Health Organization, Geneva, Switzerland, 2002.

[2] D. Lariviere, Nutritional Supplements Flexing Muscles as Growth Industry, Forbes.com, September 2015, http://www.forbes.com/ sites/davidlariviere/2013/04/19/nutritional-supplements-flexingtheir-muscles-as-growth-industry/.

[3] M. M. Robinson and X. Zhang, Traditional Medicines: Global Situation, Issues and Challenges. The World Medicines Situation, WHO, Geneva, Switzerland, 3rd edition, 2011.

[4] B. Barrett, D. Kiefer, and D. Rabago, "Assessing the risks and benefits of herbal medicine: an overview of scientific evidence," Alternative Therapies in Health and Medicine, vol. 5, no. 4, pp. 40-49, 1999.

[5] C. Avendaño and J. C. Menéndez, Medicinal Chemistry of Anticancer Drugs, Elsevier, 1st edition, 2008.

[6] F. E. Koehn and G. T. Carter, "The evolving role of natural products in drug discovery," Nature Reviews Drug Discovery, vol. 4, no. 3, pp. 206-220, 2005.

[7] A. S. Elias, G. Tesfaye, and M. Bizatu, "Aspects of common traditional medical practices applied for under-five children in Ethiopia, Oromia Region, Eastern-Harargie District, Dadar Woreda, 2011 G.C," Journal of Community Medicine \& Health Education, vol. 3, no. 6, 2013.

[8] E. d'Avigdor, W. Hans, A. Zemede, and A. Tesfaye, “The current status of knowledge of herbal medicine and medicinal plants in Fiche, Ethiopia," Journal of Ethnobiology and Ethnomedicine, vol. 10, article 38, 2014.

[9] A. Getachew, A. Dawit, G. Timotewos, and U. Kelbessa, "Perceptions and practices of modern and traditional health practitioners about traditional medicine in Shirka District, Arsi Zone, Ethiopia," Ethiopian Journal of Health Development, vol. 16, no. 1, pp. 19-29, 2002.

[10] G. Alevtina and S. Zerihun, Ethiopian Traditional and Herbal Medications and Their Interactions with Conventional Drugs, 
2009, http://ethnomed.org/clinical/pharmacy/ethiopian-herbdrug-interactions.

[11] N. J. Gakunga, K. Mugisha, D. Owiny, and P. Waako, "Effects of crude aqueous leaf extracts of Citropsis articulata and Mystroxylon aethiopicum on sex hormone levels in male albino rats," International Journal of Pharmaceutical Science Invention, vol. 3, no. 1, pp. 5-17, 2014.

[12] D. Kebede, G. Binyam, and M. Yunis, "A historical overview of traditional medicine practices and policy in Ethiopia," The Ethiopian Journal of Health Development, vol. 20, no. 2, pp. 128134, 2006.

[13] A. Mohsen and H. Masoumeh, "Knowledge, attitude and practice toward complementary and traditional medicine among Kashan health care staff, 2012," Complementary Therapies in Medicine, vol. 22, no. 1, pp. 126-132, 2014.

[14] D. Abebe, M. Zewdu, and A. Demissei, "The role of medicinal plants in health care coverage of Ethiopia, the possible integration," in Conservation and Sustainable Use of Medicinal Plants in Ethiopia, Proceedings of the National Workshop, 28 April-01 May 1998, pp. 6-21, Institute of Biodiversity Conservation and Research, Addis Ababa, Ethiopia, 2001.

[15] G. D. Alene and M. Edris, "Knowledge, attitudes and practices involved in harmful health behavior in Dembia district, Northwest Ethiopia," Ethiopian Journal of Health Development, vol. 16, no. 2, pp. 199-207, 2002.

[16] E. O. Agbaje and E. O. Babatunde, "A KAP study of the attitude and practice of traditional medicine in a contemporary Nigerian community," Central African Journal of Medicine, vol. 51, no. 5-6, pp. 58-62, 2005.

[17] A. Belayneh, Z. Asfaw, S. Demissew, and N. F. Bussa, "Medicinal plants potential and use by pastoral and agro-pastoral communities in Erer Valley of Babile Wereda, Eastern Ethiopia," Journal of Ethnobiology and Ethnomedicine, vol. 8, article 42, 2012.

[18] R. Reta, "Assessment of indigenous knowledge of medicinal plant practice and mode of service delivery in Hawassa city, Southern Ethiopia," Journal of Medicinal Plants Research, vol. 7, no. 9, pp. 517-535, 2013.

[19] B. Bekele, Z. Asfaw, B. Petros, and H. Tekie, "Ethnobotanical study of plants used for protection against insect bite and for the treatment of livestock health problems in rural areas of Akaki District, Eastern Shewa, Ethiopia," Topclass Journal of Herbal Medicine, vol. 1, no. 2, pp. 12-24, 2012.

[20] A. Kefalew, Z. Asfaw, and E. Kelbessa, "Ethnobotany of medicinal plants in Ada'a District, East Shewa Zone of Oromia Regional State, Ethiopia," Journal of Ethnobiology and Ethnomedicine, vol. 11, article 25, 2015.

[21] A. Gebre-Mariam, F. Lemma, and Y. Alemu, "Utilization of traditional medicine among inpatients in Jimma Hospital," The Ethiopian Journal of Health Development, vol. 7, no. 2, pp. 87-91, 1993.

[22] S. K. Jain and S. Srivastava, "Traditional uses of some Indian plants among islanders of the Indian Ocean," Indian Journal of Traditional Knowledge, vol. 4, no. 4, pp. 345-357, 2005.

[23] R. H. Yadav, "Medicinal plants in folk medicine system of Ethiopia," Journal of Poisonous and Medicinal Plants Research, vol. 1, no. 1, pp. 7-11, 2013. 


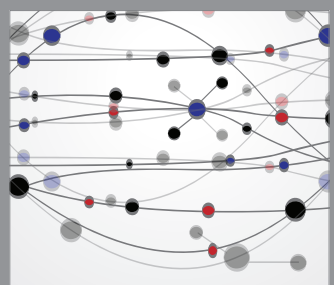

The Scientific World Journal
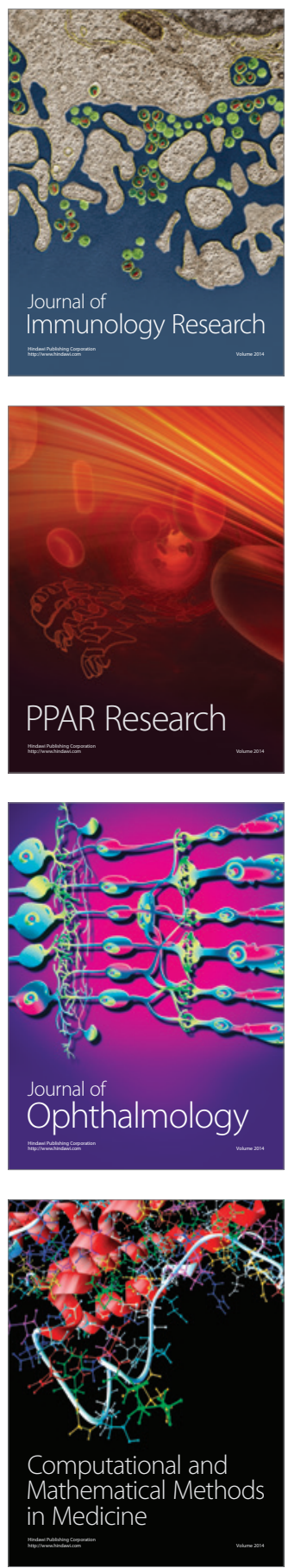

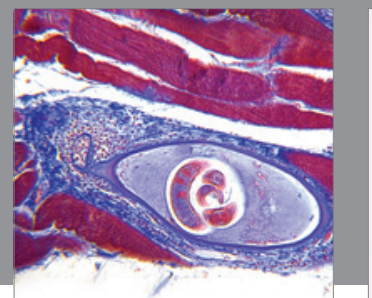

Gastroenterology

Research and Practice
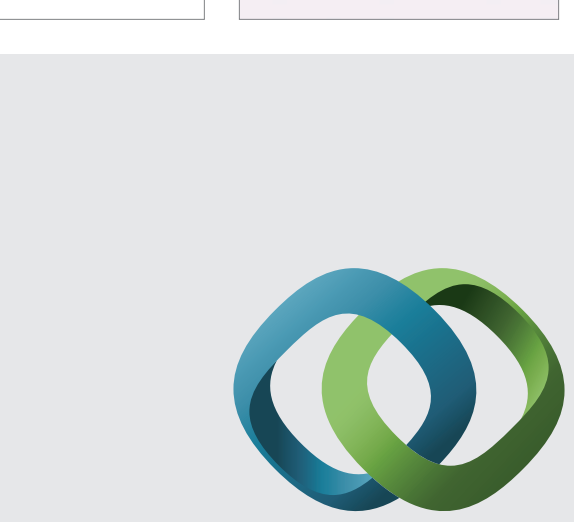

\section{Hindawi}

Submit your manuscripts at

http://www.hindawi.com
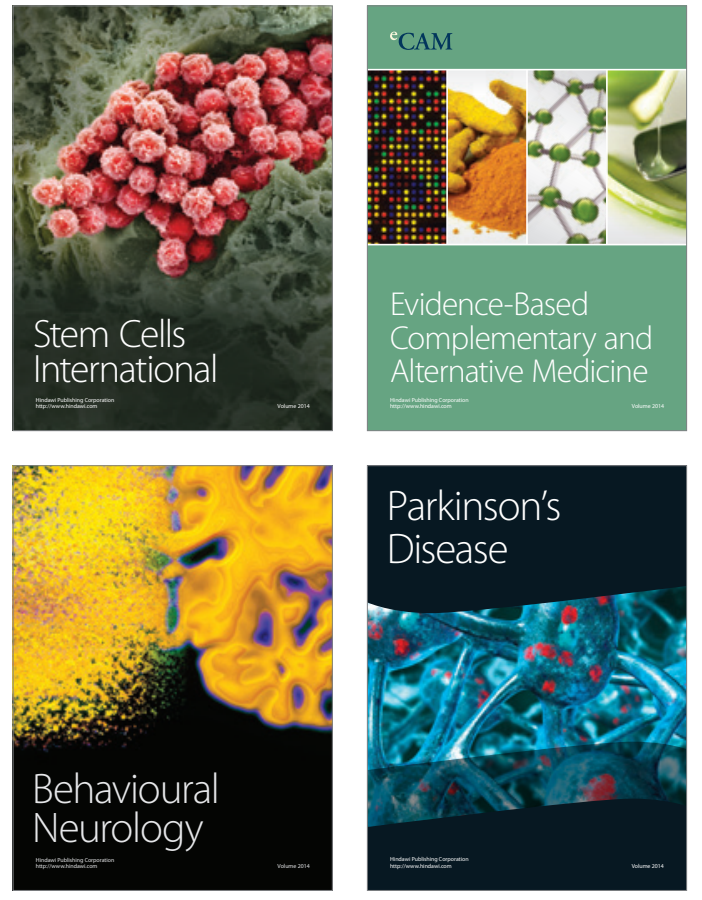
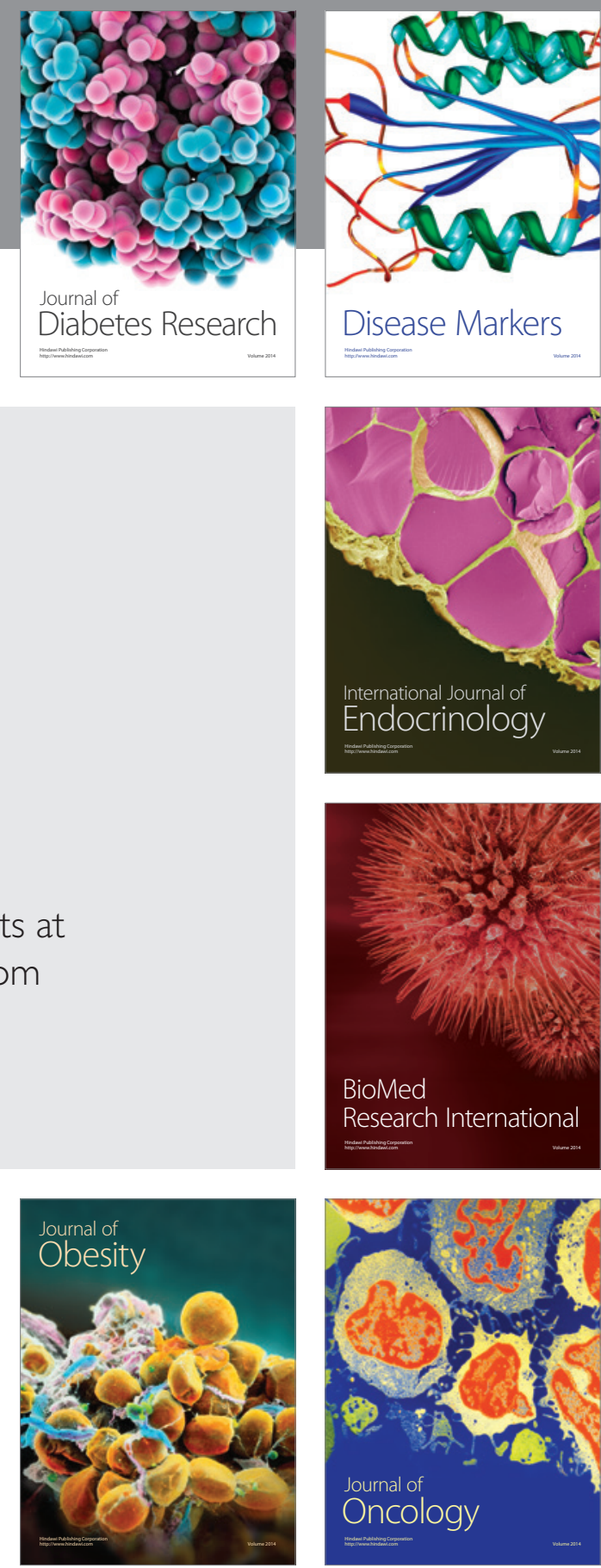

Disease Markers
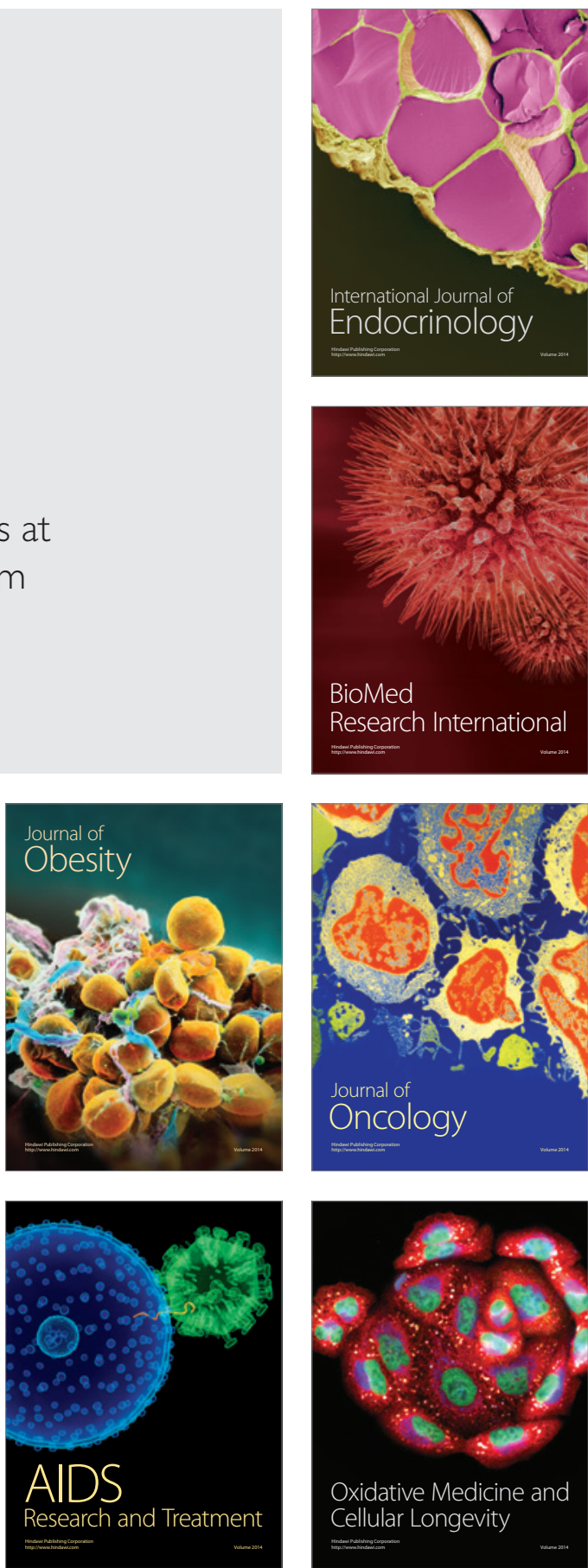